Editorial

\title{
Editorial: Quantifying Higher Education: Governing Universities and Academics by Numbers
}

\author{
Maarten Hillebrandt ${ }^{1, *}$ and Michael Huber ${ }^{2}$ \\ ${ }^{1}$ Faculty of Law, University of Helsinki, 00101 Helsinki, Finland; E-Mail: maarten.hillebrandt@helsinki.fi \\ 2 Faculty of Sociology, Bielefeld University, 33615 Bielefeld, Germany; E-Mail: michael.huber@uni-bielefeld.de \\ * Corresponding author
}

Submitted: 29 October 2019 | Published: 9 April 2020

\begin{abstract}
Over the past decades, 'governing by numbers' has taken a flight in the higher education sector. Performance-based budgeting and quality assurance schemes orient universities to new objectives, while rankings have globalised the metrified observation of higher education at large. Where previously no indicators existed, they are being introduced; where indicators already existed, they are being standardised for purposes of comparison. This thematic issue aims to work towards a more comprehensive understanding of the growing diversity of quantification-based instruments in higher education sectors in three European countries. The effects of quantification are noticed at all levels of the higher education system, from policy makers at the top of the regulatory pyramid down to students and academic staff. Yet even quantifiers outside of the regulatory system, such as ranking and metrics organisations, may have an important bearing on the operation of the university organisation and the sector at large. Thus, an entire governance landscape emerges in which actors at various levels turn to numbers for guidance. The articles in this thematic issue analyse the life cycle of such numbers, from their origins, through to their production and finally, their consequences. This editorial outlines the central questions and overarching issues addressed by the thematic issue and introduces its various contributions.
\end{abstract}

\section{Keywords}

comparative policy studies; higher education governance; managerialism; performance indicators; quantification; regulation

Issue

This editorial is part of the issue "Quantifying Higher Education: Governing Universities and Academics by Numbers" edited by Maarten Hillebrandt (University of Helsinki, Finland) and Michael Huber (University of Bielefeld, Germany).

(C) 2020 by the authors; licensee Cogitatio (Lisbon, Portugal). This article is licensed under a Creative Commons Attribution 4.0 International License (CC BY).

\section{Public Sector Quantification in the Limelight}

Twenty-five years after Porter (1995) focussed attention on the centrality of numbers in the conduct of modern social and political life, the place of quantification in the limelight of the social sciences appears undiminished. Indeed, as overview articles by Espeland and Stevens (2009) or Popp Berman and Hirschman (2018) have shown, over time, quantification research has increasingly branched out, become institutionalised, and settled on a division of labour.

One of the critical assumptions of quantification studies or 'governance by numbers' is the idea that numbers transform organisational and political behaviour. Two powerful time diagnoses by Power (1997) and, more recently, Dahler-Larsen (2012) have argued that late modern society is characterised by relentless efforts at audit and evaluation. This trend, in a memorable phrase by Miller (2001, pp. 381-282), has generated an "avalanche of numbers" for decision making in "almost any organization." This has had remarkable effects. As early as 1999, Hood, Scott, James, Jones and Travers, in a landmark study, estimated that policies for control inside government cost $€ 1$ billion per year in the UK alone (Hood et al., 1999, p. 42). Since then, the scale of quality-controlling, competition-inducing, and waste-watching in the pub- 
lic sector seems only to have grown, although accents may have changed and intensities differ across countries (Hood, 2007; Hood, James, Peters, \& Scott, 2004). Thus, the promise of governance by numbers not only comes with a price tag, but also alters routines and certainties; and that requires academic scrutiny.

It is in this context that this thematic issue turns its attention to the advent of quantification in the higher education sector where 'governing by numbers' appears to have taken a flight. Performance-based budgeting and quality assurance schemes orients universities to new objectives (Ferlie, Musselin, \& Andresani, 2008; Huber \& Hillebrandt, 2019), while rankings have globalised the metrified observation of higher education at large (Espeland \& Sauder, 2007, 2016). Where previously no indicators existed, they are being introduced; where indicators already existed, they are being standardised for purposes of comparison. The proliferation and diversification of quantification has already been diagnosed; the next step is to analyse its manifestations and effects in the fields it is applied to.

\section{Puzzles Addressed in This Thematic Issue}

This thematic issue is the result of a workshop on quantification in higher education that was held at Bielefeld University in March 2019. Together, the articles present empirical research from three western European countries (England, Germany, the Netherlands), covering various manifestations of quantification, including rankings, finance models, quality assurance, and performance analytics. In spite of their thematic and conceptual diversity, the various contributions are united by a number of common concerns and recurrent themes at the core of quantification studies. We would here like to highlight two of them.

First, the contributions provide further insight into what could be labelled 'the life cycle of quantification', i.e., covering instruments from their origins, through to their production, and finally, their consequences. Starting off from a perceived weaving fault in the existing system, policy makers typically develop rudimentary systems of indicators and targets in order to clarify lines of accountability, increase efficiency, or enhance the innovative potential of universities. Problems often emerge when quantification instruments run into the complexities of a differentiated regulatory field. In higher education, this encompasses the multiple tasks (teaching/research) and foci (fundamental/applied research, different disciplines) of universities, as well as the differential systems within which they and their staff operate (tenured/non-tenured positions, national educational systems). This typically casts different groups within the system against each other. Depending on the situation at hand, this may be universities against ministries, professors against junior academics, or resourceintensive against student-intensive disciplines. The consequences of these quantification-induced conflicts de- pend on the question how much 'damage' a system is willing to accept. Here, there appear to be marked differences depending on national legacies, with the German and Dutch system more careful and the English system more far-reaching.

A second theme of the articles concerns the 'regulatory nexus in higher education.' Regulators at ministries and university administrations, confronted with political and societal pressures as well as international norms and standards, are thought to fall back on quantification in order to raise their profile in the competition for scarce resources, be it money, students, or prestige. In this account, faculties and academic staff are the largely passive but resisting recipients of their administration's and external regulators' steering strategies (Schimank, 2005; Strathern, 2000). The contributions in this thematic issue question the schematic nature of this account, sketching a more dynamic picture of interactions between policy makers and professionals. The former are often recruited from the latter and show a reluctance to implement too far-reaching quantification instruments, while professionals themselves often complain about inefficiency and a lack of tangible recognition of their achievements. Moreover, several contributions raise attention to the pivotal role of newly emerging economic actors outside of the regulatory system, such as ranking and metrics organisations. The new calculative infrastructures that these actors create are critical in the understanding both of the diffusion of numbers as well as specific constraints to governance.

\section{The Articles in This Thematic Issue}

The contributions to the thematic issue are clustered around these two themes. The articles by Kandiko Howson and Buckley (2020), Dix, Kaltenbrunner, Tijdink, Valkenburg, and de Rijcke (2020), and Huber (2020) take up aspects of the life cycle theme and offer case studies of quantification in each of the three countries illustrating how governance by numbers is designed, and how the various actors respond to signals of dysfunctionality that emerge over time. The regulatory nexus theme includes articles by Ringel, Brankovic, and Werron (2020), Hillebrandt (2020), and Krüger (2020). These authors address the emergence and usage of new numerical data infrastructures, paying special attention to the administrative and organisational capacities that these infrastructures enable, but also require.

Kandiko Howson and Buckley (2020) describe the career of quantification as a way to measure learning gain in UK undergraduate education. From the 1990s onward, attempts by government regulators to create a market for higher education required an informational level playing field, which quantification was meant to deliver. Since tuition fees nearly trebled to $£ 9,000$ per annum in 2012 , the drive to give students demonstrable 'value for money' increased. Such value, the authors point out, is routinely defined in terms of "'corporate culture' [for 
universities] and individual monetary gain [for students]" (Kandiko Howson \& Buckley, 2020, p. 7). In this context, measuring learning quality logically makes up the latest incarnation of this marketisation agenda. The authors offer a detailed account of the vast efforts and material resources that the UK regulator has expended on translating this ideal into reality. Several parties were included in pilot projects for the development of suitable indicators. The efforts began to be resisted when affected actors noticed that indicators were borrowed from the rather dissimilar US context, and were going to be applied with little heed to disciplinary and other variations within universities. As specific policies faltered, the data remained in place. In the end, a situation emerges of numbers in search of a purpose. Or, in the authors' words, "without a rationale for developing, selecting and using measures the number...becomes an end in itself" (Kandiko Howson \& Buckley, 2020, p. 11).

The contribution of Dix et al. (2020) focusses on the Dutch context. Their case consists of research departments within a medical centre which are confronted with a new performance measurement instrument that directly affects their funding situation. Like Kandiko Howson and Buckley (2020), the case emerges against a backdrop of marketisation. However, the author's approach to the concept of 'value' is rather different. Borrowing from the notion of 'economies of worth' coined by Boltanski and Thévenot, the authors analyse a controversy over quantification with quite real consequences: The question whether a 'market language' of value should determine the allocation of scarce resources. The analysis lays bare the 'epistemic language' by which opponents of market-based competition criticise the quantification instrument in place. The strength of this article lies in its detailed analysis of sixteen interviews conducted with actors across the organisation, which allows for a nuanced account. While quantification is proposed as a way of trading arbitrary finance inequalities for a more transparent system, management also proves to be sensitive to some of the discontents voiced by opponents of marketisation. For example, it is unwilling to put the long-term financial viability of departments at risk. The article thus shows that arguments for and against quantification-based marketisation can get blended. In the authors" words, "we should be careful in depicting higher education as populated by 'market universities' fully enmeshed in 'epistemic capitalism"' (Dix et al., 2020, pp. 23-24).

The article by Huber (2020) complements the previous two contributions by addressing the role of financial quantification in a German university. University management is represented as a team charged with bridging the expectations gap between state regulators and academics. The role of quantification in this balancing act is inherently fragmented and uneven: Rather than steering the university systematically towards a unified goal, various types of numbers introduced at different moments in time address a multiplicity of audiences within the university organisations. This is not accidental. Rather, multiple policies are in place to remedy the perverse effects of other policies, leading to a conceptual representation of university quantification as foremost an organic, layered whole. Here, the author refers to the organisational sociology of Luhmann: "reforms do not form part of a grand plan, but recurrently intervene to repair the shortcomings and unintended effects of previous interventions" (Huber, 2020, p. 26). The dynamic and multicentred model of quantification allows for a number of interesting conclusions. It appears clear that reality of quantification in practice is inherently a 'messy affair' without one single premeditated logic. Yet, at the end of the day, the layering of quantification succeeds, however transiently, in creating a certain stability of purpose: management by numbers "can to a large extent be incorporated into the traditional organisational form of the university" (Huber, 2020, p. 34).

The contribution by Ringel et al. (2020) shifts the focus in several respects. Rather than the effects of quantification, it considers its preconditions. The selected case, that of higher education rankings, constitutes a form of quantification that has over the past decades increasingly 'gone global' (see also Brankovic, Ringel, \& Werron, 2018). The authors bring attention to an aspect that has hitherto received scarce attention in this lively research field: The material preconditions for the creation and sustenance of rankings. A key reason for the 'rankings boom' in higher education and other areas, the authors argue, lies in the organisational turn. They demonstrate how organisations offer capacities for the creation and dissemination of ranking that vastly exceed those of individuals. As a result, ranking organisations are able to publish increasingly sophisticated rankings with a regular frequency, while offering the 'maintenance work' required to bind them to ever-more diverse audiences of 'consumers.' Thus, as the authors point out, "the organizational production of rankings provides an elementary and hitherto overlooked infrastructure" accounting for their success and pervasiveness (Ringel et al., 2020, p. 44). The article's focus offers an interesting additional perspective by 'turning the camera' on a group of actors that fall outside of the regulatory context proper, but which nevertheless have gathered considerable clout in parts of the higher education sector, in a trend that has simultaneously emerged in other competitive sectors such as hospitality, catering, and health care.

In his article, Hillebrandt (2020) observes that although gathering quantified data is a growing business everywhere, in Germany actual reliance on this data is limited. What explains the limited effect of regulatory control through numbers in Germany? With the catchy metaphor of the Mercedes that is left in the garage, the author explores three hypotheses: First, a legal hypothesis that suggests quantification being curbed by legal protections of higher education providers: The state wants 'to drive the Mercedes,' but legal protections wreck this strategy. The state gives up on steering through numbers 
while it continues to collect data. A second, labelled dysfunctionality hypothesis holds that regulators see quantification as a flawed and impracticable pursuit. The Mercedes may be shiny, but cannot be driven safely. The flaws and inaccuracies of steering by numbers are considered too momentous to risk failure. The third hypothesis reflects the federal structure of Germany and suggests that federal comparison exposes differences and thus potential weaknesses of the responsible Länder (German states): as such, the Mercedes better stays in the garage. The article finds that all three hypotheses contribute to an explanation of the German higher education sector's engagement with quantification, but it also shows that the Mercedes is driven sub rosa, meaning that any governing by numbers "functions in a largely tempered, hybrid, and untransparent manner" (Hillebrandt, 2020, p. 55).

The article by Krüger (2020) forms a suitable concluding note to the empirical section of this thematic issue. In her contribution, Krüger (2020) goes in search of 'quantification 2.0' in the amalgam of commercially exploited data infrastructures that have begun to emerge out of increasingly vast bibliometric data sets. Beyond marketisation and managerialism, she argues, students of quantification in the higher education sector should not overlook ongoing technological development as a push factor in its own right. As the author states, "bibliometric data has turned into a self-serving end while their providers are constantly seeking for new tools to make use of them" (Krüger, 2020, p. 59). Organisations in the higher education sector and beyond have begun to collect data without any specific purpose, under the (ideologically informed) supposition that eventually uses will be found for it that will improve organizational performance. New functionalities invite academics, managers, and regulators to engage with-and even create-data in novel ways, thereby fomenting alternative ways of regarding academic work in relation to the individual and (a reinvented notion of) the wider profession. Does all of this spell a dystopian future in which untransparent private firms remake the academic profession in their commercial image? The author remains cautious here, by pointing out that in spite of its performativities, the various new potential uses of 'quantification 2.0' are bounded by notions of customer (academic community) acceptance among developers.

Finally, a commentary by Hamann (2020) reflects on the findings in the articles that form part of this thematic issue, focussing in particular on the sociological implications of higher education governance by numbers. Setting out from the Foucauldian dyad of power and discipline, he places the phenomenon of academic quantification primarily in the light of what he describes as 'panopticism': The creation of new avenues for numberbased mutual observation that rearrange interactions and create new forms of control. 'Numerocratic panopticism' however reveals certain dynamics that depart from the classic panoptic gaze: it increases the number of observers, is freed from spatial constraints, and its norma- tive programme is more open-ended. This, the author argues, demonstrates that "governance by numbers is not only an epitome of classical panopticism but...also a panopticon reversed" (Hamann, 2020, p. 70).

All in all, the various contributions offer a glimpse onto a wider higher education governance landscape oriented on numbers for guidance. In doing so, they show a considerable attention to the details and intricacies of specific policy instruments, and the way in which they come about. As it turns out, such attention to detail often pays off as it highlights where problems occur and thus, how the fault lines of policy conflict are likely to play out. It becomes clear from the various empirical studies that in most instances of quantification, such problems do emerge. Typically, quantification-based steering instruments require fundamental reform within a few years after their introduction. We attribute this general observation to the short-term focus of many indicators, which means that their dysfunctionalities take some time to become apparent. Yet, the contributions to this thematic issue inevitably lead to the conclusion that, even when repeatedly bruised and floored, the appeal of higher education quantification continues undiminished.

\section{Acknowledgments}

The authors would like to thank the participants to the workshop "Quantifying Higher Education: Origins, Production, Consequences," that was held at Bielefeld University on 28-29 March 2019. The authors further gratefully acknowledge funding received from the Deutsche Forschungsgemeinschaft (DFG) (Project No. 627097) under the Open Research Area Scheme (Project Title: QUAD-Quantification, Administrative Capacity and Democracy, 2016-2019).

\section{Conflict of Interests}

The authors declare no conflict of interests.

\section{References}

Brankovic, J., Ringel, L., \& Werron, T. (2018). How rankings produce competition: The case of global university rankings. Zeitschrift Für Soziologie, 47(4), 270-288.

Dahler-Larsen, P. (2012). The evaluation society. Redwood City, CA: Stanford University Press.

Dix, G., Kaltenbrunner, W., Tijdink, J., Valkenburg, G., \& de Rijcke, S. (2020). Algorithmic allocation: Untangling rival considerations of fairness in research management. Politics and Governance, 8(2), 15-25.

Espeland, W. N., \& Sauder, M. (2007). Rankings and reactivity: How public measures recreate social worlds. American Journal of Sociology, 113(1), 1-40.

Espeland, W. N., \& Sauder, M. (2016). Engines of anxiety: Academic rankings, reputation, and accountability. New York, NY: Sage. 
Espeland, W. N., \& Stevens, M. L. (2009). A sociology of quantification. European Journal of Sociology, 49(3), 401-436.

Ferlie, E., Musselin, C., \& Andresani, G. (2008). The steering of higher education systems: A public management perspective. Higher Education, 56, 325-348.

Hamann, J. (2020). Governance by numbers: A panopticon reversed? Politics and Governance, 8(2), 68-71.

Hillebrandt, M. (2020). Keeping one's shiny Mercedes in the garage: Why higher education quantification never really took off in Germany. Politics and Governance, 8(2), 48-57.

Hood, C. (2007). Public service management by numbers: Why does it vary? Where has it come from? What are the gaps and the puzzles? Public Money and Management, 27, 95-102.

Hood, C., James, O., Peters, B. G., \& Scott, C. (Eds.). (2004). Controlling modern government: Variety, commonality and change. Cheltenham: Edward Elgar.

Hood, C., Scott, C., James, O., Jones, G., \& Travers, T. (1999). Regulation inside government: Wastewatchers, quality police and sleaze-busters. Oxford: Oxford University Press.

Huber, M. (2020). Steered by numbers: How quantification differentiates the reform of a German university. Politics and Governance, 8(2), 26-35.

Huber, M., \& Hillebrandt, M. (2019). "Pay for promise" in higher education: The influence of NPM on resource allocation in German universities. Historical Social Research, 44(2), 247-269.

Kandiko Howson, C., \& Buckley, A. (2020). Quantifying learning: Measuring student outcomes in higher education in England. Politics and Governance, 8(2), 6-14.

Krüger, A. K. (2020). Quantification 2.0? Bibliometric infrastructures in academic evaluation. Politics and Governance, 8(2), 58-67.

Miller, P. (2001). Governing by numbers: Why calculative practices matter. Social Research, 68(2), 379-396.

Popp Berman, E., \& Hirschman, D. (2018). The sociology of quantification: Where are we now? Comparative Sociology, 47(3), 257-266.

Porter, T. (1995). Trust in numbers: The pursuit of objectivity in science and public life. Princeton, NJ: Princeton University Press.

Power, M. (1997). The audit society. Oxford: Oxford University Press.

Ringel, L., Brankovic, J., \& Werron, T. (2020). The organizational engine of rankings: Connecting "new" and "old" institutionalism. Politics and Governance, 8(2), 36-47.

Schimank, U. (2005). New public management and the academic profession: Reflections on the German situation. Minerva, 43, 361-376.

Strathern, M. (Ed.). (2000). Audit cultures: Anthropological studies in accountability, ethics and the academy. London: Routledge.

\section{About the Authors}
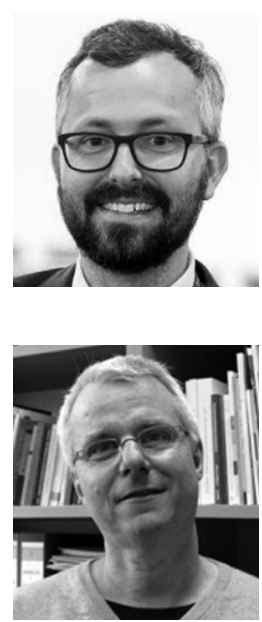

Maarten Hillebrandt is Postdoctoral Researcher at the Erik Castrén Institute, University of Helsinki, where he is involved in a research project on the transparency of EU decision making. Previously, he participated in the international comparative ORA-funded research project 'Quantification, Administrative Capacity and Democracy' (2016-2019), in which researchers from the London School of Economics, Paris MinesTech, Bielefeld University, Helmut Schmidt University Hamburg, and Leiden University were co-collaborators. Maarten specialises in EU institutional law and politics, government transparency policy, and quantification.

Michael Huber is Professor of Sociology at the Department of Sociology at Bielefeld University. His research is focused on organisational sociology, higher education studies, and regulatory policymaking, more specifically, risk-based regulation. 